Jovanka Vukmirović1, Aleksandra Vukmirović ${ }^{2}$, Dragan Vukmirović ${ }^{1}$ University of Belgrade, Faculty of Organizational Sciences

${ }^{2}$ Stata.rs Itd Belgrade, Milutina Milankovića 132/9 Belgrade ${ }^{3}$ Statistical Office of the Republic of Serbia, Milana Rakića 5 Belgrade

\title{
Mapping of the Business Infrastructure in Serbia with a Special View at Brownfield and Greenfield
}

UDC: UDC: $332.122: 338.45(497.11)$

DOI: 10.7595/management.fon.2014.0008

SPIN'13, Belgrade, 05-06. November 2013.

\begin{abstract}
Contemporary business dictionaries lack a precise definition of the notion of business infrastructure. Also, there is an open question as to what are all the things that comprise a business infrastructure. In Serbia, there is not a legislative framework yet which recognizes and stimulates its development by categories and geographic position. Parallel to the lack of notional and legislative frameworks, we can also observe numerous activities in the field of creation of development policies and project investments in concrete facilities and sites. During the previous several mandates (since 2007), the Government of Serbia has stimulated the development of business infrastructure throughout the country using the budget funds. During the same period, significant donor funds have been spent precisely for the projects in the sphere of enhancement of business infrastructure in Serbia. In addition to the definitions provided for a set of important notions, the paper also presents a structural analysis based on the results of the survey / mapping of business infrastructure. It also shows the methodological procedure with a special view at the socalled brownfield and greenfield potentials. Also, the results of the survey have been considered within a general socio-economic context with a critical view at the effects of the implemented development policies.
\end{abstract}

Keywords: business infrastructure, mapping, industrial zones, brownfield, greenfield.

\section{Introduction - basic definitions and methodological foundation}

"The registration of the first clusters and incubators in 2005 marked the beginning of the development of business infrastructure in Serbia, with the goal to increase the competitiveness of the domestic economy, attract foreign investments and stimulate a more balanced regional development through the founding of industrial and technological parks, as well as industrial zones. (http://bif.rs/2012/05/biznis-i-finansije-87-poslovnainfrastruktura-srbije/)

Business infrastructure represents an institutionalized logistical support to enterprises and entrepreneurs that are located at one site, with the goal that their individual development should render positive effects on the overall socio-economic position of the community. From the aspect of the local and regional development, it is very important that the development of business infrastructure is adjusted to the needs and development potentials (geopolitical, natural, human, technological, etc.) of the given area. In this way, comparative advantages are stimulated and the local and regional competitiveness is directly increased. Types of business infrastructure. Business infrastructure includes:

- Cooperatives and logistical centres (Business Support Centre)

- Clusters

- Business incubators

- Technological parks

- Industrial parks

- Industrial zones

- Free zones, and

- From the aspect of the current state of economy, brownfield facilities and sites certainly must also be added to this category. 
Cooperatives and logistical centres (Business Support Centre) are independent business subjects or departments within some existing structure which deals with rural development. They directly participate in the process of creating a new value by providing support to primary agricultural producers in the form of: enhancing the knowledge and adopting new technologies, quality control, sorting, gauging, warehousing, packaging, protection of the geographic origin, branding, promotion, placement and collection. They are of particular importance for rural development and the lack of this kind of support directly causes demographic depletion and destruction of the already week economy of rural areas.

Business incubators are business companies which primarily provide office space for newly-founded enterprises and entrepreneurial stores thus minimizing the initial costs of starting up a business. The "tenants" of business incubators share costs of administration, technical and other services which also significantly relaxes them in financial terms over the period of 3-5 years after which it is purported that they should leave the incubator and continue their independent operations.

Technological park (or science park) is a specific type of business incubator intended for encouraging innovations through linking scientific work with operations of enterprises and entrepreneurial stores, especially in the fields of advanced technologies (electronic communications, electronics, software creation, etc.). Science parks exist next to universities, that is, technical and technological faculties.

Innovation clusters are groups of innovative small, medium and large enterprises and research organizations that operate in a certain sector and are regionally concentrated. Clusters are founded with an intention to stimulate innovative activities of enterprises and a technological transfer within the cluster through a process of knowledge and experience exchange (European Commission 2006, p. 9). According to Porter's definition, clusters are geographic concentrations of interconnected companies of related and different activities that compete in the given field of operations, but also cooperate. A cluster is interconnected on the basis of joint interests and needs in the sphere of procurement, sale, specialized services, work force and other resources.

Free zone is a part of the territory of the Republic of Serbia which is specifically bounded and marked, and where activities are performed under the conditions stipulated by the Law on Free Zones which purport business operations in a duty-free regime when exporting products manufactured within the free zone. (Law on Free Zones, art. 2, para. 1).

Industrial park is an enterprise founded with a goal to manage an industrial zone in terms of planning its expansion and infrastructural equipping. An industrial park may provide information and services (obtaining building permits, etc.) of interest for potential users of the land within the industrial zone.

Industrial zone is a plotted construction land equipped with the necessary utility infrastructure, including an inner network of roads, water supply, sewerage, electricity and telecommunications, which is intended for sale or renting with the aim to instigate industrial development (draft Law on Industrial Parks, 2006). A major advantage of zones and parks from the ecological aspect is that they concentrate industrial production at sites which are equipped for that in utility and infrastructural terms, and which are sufficiently distanced from urban areas.

Brownfield signifies abandoned business facilities and sites, which burden the environment in an economic, ecological and aesthetic sense. A revitalization of brownfield most frequently surpasses the economic powers of the local communities which are essentially those that are most hit by its negative effects.

Army brownfield is a term compounded by establishing the Fund for the Defence System Reform in 2004, that is, by enacting the Master Plan for disposing of army real estate from 2006. Since then, a new category of brownfield has appeared in many municipalities comprising facilities and sites that previously had a military purpose. These are most frequently land complexes (former training fields, airports, etc.) and facilities (military barracks, warehouses, army social centres, etc.). It is estimated that the total value of the army assets offered in the market amounts to four billion euros. Local self-governments on the territories of which these facilities are located have a priority in their purchase. 


\section{Methodology for mapping the business infrastructure}

The basic goal of mapping the business infrastructure is to create a unique register of business incubators, cooperatives and logistical centres, clusters, technological parks, industrial zones and brownfield sites in the Republic of Serbia.

The methodology for mapping the business infrastructure entails the following phases:

- Analysis of the legal framework (laws, by-laws and strategic documents)

- Snap-shot of the current state (mapping)

- Analysis of the results with a special view at brownfield and greenfield

\subsection{Legal framework for the establishment of the business infrastructure}

A legal framework that would completely regulate the sphere of business infrastructure and define competencies and development priorities does not exist in Serbia. The following documents are of importance for the mapping of the business infrastructure:

Regional Development Strategy of the Republic of Serbia for the period 2007 - 2012 considers business infrastructure development projects (industrial zones, business parks, business incubators, innovation centres, information and advisory centres) in a context of achieving a uniformed regional development.

The 2008 Regional Development Law recognizes the National Agency for Regional Development, and regional and district development agencies as institutions that follow and implement measures and carry out development projects for the enhancement of economic infrastructure.

Laws on cooperatives from the previous period (The Official Gazette of the SFRY 13/65, 7/67, the Official Gazette of the SRS 57/89, the Official Gazette of the RS 46/95, the Official Gazette of the FRY 41/96 and $12 / 98)$, regardless of whether abolished or not, are practically not applicable in today's business environment. The draft Law on Cooperatives that should regulate this area and give a strong impetus to cooperatives' members was put up for public debate back in 2011, but is still far from being adopted.

The Law on the Spatial Plan of the Republic of Serbia for the period 2010 - 2020 provides a description of the notions and a list by categories of the existing facilities of business infrastructure. The spatial plan provides for a creation of a cadastre of brownfield sites and a strategy for reviving industrial brownfield. Also, according to the spatial plan an increase in the competitiveness of a certain area is achieved by founding industrial and technological parks, and industrial zones. Concentrating complementary business activities in one area enables a dynamic development of those activities, as well as development of accompanying service activities.

\subsection{Snap-shot of the current state (mapping)}

Map of the business infrastructure. It is not known exactly how many cooperatives there are in Serbia or how they function. According to the latest available data of 2009 (Source: Satellite accounts for cooperative economy of the Republic of Serbia 2009, (2011), Andra Miloic et al.), the cooperative sector in Serbia comprised 2124 cooperatives and 16 cooperative associations, which accounts for a total of 2140 businesses. Out of that number, $67.1 \%$ are agricultural cooperatives. (Youth and student cooperatives have a share of $17.8 \%$, housing cooperatives $6.9 \%$, the share of crafts ones amounts to $4.1 \%$, while the share of all other cooperatives is $4.2 \%$ ). In 2009, the gross added value (GAV) in the cooperative sector (total) was RSD 4256.2 million, which accounted for a $0.27 \%$ share in the economy of the country. At the same time, the GAV of cooperatives and cooperative associations was on a continuous decline in the period 2007-2009. To interpret this freely, the aggregate values of the cooperative sector point at a long period of institutional lack of care, as well as at the negative effects of the transitional restructuring of the national economy on the business operations of the cooperative sector. 
There are 23 incubators in Serbia: Novi Sad, Subotica, Zrenjanin, Bački Petrovac, Pancevo, Senta, Kanjiza, Beočin, Niš, Vranje, Zajecar, Bor, Knjaževac, Prokuplje, Medvedja, Kragujevac, Rača, Kruševac, Užice, Valjevo and Kraljevo, Zvezdara and Rakovica, out of which only few operate with full capacity. The business incubators have been created on an assumption that comfortable and free business premises and almost free logistical support (bookkeeping, legal affairs, insight into new technologies, etc.) will be a sufficiently strong incentive for founding micro and small-size enterprises. It remains unclear why even with such attractive incentives the incubators remained without "tenants." The survival of the incubators is considered within the context of financial unsustainability - the funds obtained from collections for the services rendered are not sufficient, while the donors' projects from which they were financed are exhausted.

Clusters provide different services to their members - most frequently these are organizations of seminars and conferences, visits and joint promotions at fairs, as well as public advocacy. The main advantage for the members of a cluster is reflected in the possibilities of joint market approach, which opens up opportunities for small enterprises to take a part in "big" business operations. It is not known exactly how many clusters there are in Serbia. There are 58 of them registered at the Business Registers Agency, while a study of clusters in Serbia from 2011 (Analysis of the state of business infrastructure in the Republic of Serbia, D.Mijacic) gives a short description and contact data for a total of 85 clusters. Similarly to business incubators, one of the biggest problems for the future of the clusters is financial sustainability. Taking into account that the majority of them have remained without donors' funds, the survival of the clusters directly depends on the ability of their employees to provide financing through project activities.

There are 11 free zones in Serbia (Subotica, Novi Sad, Šabac, Užice, Zrenjanin, Smederevo, Svilajnac, Kragujevac, Niš and Pirot), and there is also a free zone in Apatin currently being founded (Source: http://www.mrrls.gov.rs/sites/default/files/attachment/industrijskezoneuSrbiji.pdf). There are two technological parks, in Vršac and Subotica, and there is a plan to found three more technological parks, in Niš, Indjija and Novi Sad. The number of industrial zones in Serbia is not precisely established, but it is known that there are only two enterprises that deal with the managing of industrial zones, that is, that function as industrial parks - in Subotica and Vršac.

\section{Mapping of the brownfield}

Most of the brownfield sites in Serbia represent an inglorious inheritance from the period of the socialist economy, the past work of numerous generations that built this society during the second half of $20^{\text {th }}$ century. Ruined, abandoned factories, heating plants, business buildings, warehouses, pavilions, training fields, etc. are scattered throughout Serbia, from the biggest cities to the smallest towns and nobody can, not even approximately, say how many of such facilities and sites there are, what their original intended use used to be, what their capacities and floor space are, etc. The seriousness of the brownfield problem in Serbia is inversely proportionate to the activities related to its solving. During the past decade, there was a lack of systematic and organized approach to any reactivation of the brownfield from the state level, while occasional examples of good practice were more a result of some ad hoc activity in some towns and municipalities, linked mostly to concrete investment projects (Reactivation of the brownfield in Serbia, Systematic approach or ad hoc solutions, SCTM Beograd, 2011).

This paper shows the results of mapping the brownfield - a survey that was conducted during October and November 2013 by the Standing Conference of Towns and Municipalities (SCTM) within the project "Support to local self-governments in Serbia within the European integrations process" - component IV: Enhancement of the business climate at the local level. The basic activities were aimed at collecting data from the local administrations (local self-government units, LSGU) which are not unified within any system and which are of exceptional importance for the creation of development policies at the local, regional and national levels.

The survey included all LSGU except Belgrade, which, due to its specificity and size, is not comparable with other LSGU, that is, it must be the subject of a separate study. Out of 144 LSGU, 81 LSGU (56\%) responded and submitted data on 397 brownfield facilities and sites, which represents a significant basis for drawing conclusions. The results of this survey are reliable to the degree to which the data submitted by the LSGU are reliable. 
The total area of the mapped BF facilities amounts to $2,337,304 \mathrm{~m}^{2}$, while the area on which these facilities are located amounts to approximately 9742 hectares. Taking into account that most of the sites we do not use today and treat as brownfield were created in the period of responsible socio-economic thinking-through from the second half of $20^{\text {th }}$ century, their geo-strategic position is perhaps even today their greatest value. The average distance from a major road is $2.6 \mathrm{~km}$, but if the extremes (Kneževac $40 \mathrm{~km}$, Petrovac na Mlavi $25.3 \mathrm{~km}$ and Trgovište $27.2 \mathrm{~km}$ ) are excluded, the average distance of the mapped brownfield sites from the major roads is $1.2 \mathrm{~km}$. The average distance of a motorway is $41.4 \mathrm{~km}$ and if we exclude from the general average the LSGU from the Zlatibor and Raška districts (Užice 133 km, Čajetina 150 km, Kosjerić 109 km, Nova Varoš 196 km, Novi Pazar 175 km), the average distance of the mapped brownfield sites from a motorway is $31.6 \mathrm{~km}$. The average distance from a railway track amounts to $10.8 \mathrm{~km}$, while the average distance from the closest airport (Surčin or Niš) is $110 \mathrm{~km}$.

In addition to the good position in relation to main traffic lines, a particular value of the brownfield facilities and sites is reflected in their infrastructural equipment. Almost all of them are equipped with high-voltage network $(91.1 \%)$ and land telephone lines $(92.4 \%)$. The broadband internet has reached $75 \%$ of the BF facilities, with the possibility of gas connection existing in $48 \%$ of the BF facilities, while in the case of $25 \%$ of the mapped brownfield facilities there is a possibility of enlarging the plot.

From the aspect of the local, regional and national economies, the brownfield simultaneously represents both a large developmental potential and a large socio-economic burden. There are good results that have been achieved in the developed EU countries by using a policy based on two foundations: 1 . The state and/or local community separately stimulate project activities/investments if they also contain a component of brownfield revitalization; 2. The LSGU uses fiscal measures to demotivate owners of the brownfield - by using high taxes for a lack of use or not intended use of the facilities and sites, the local community discourages the owners of the brownfield and practically forces them to come up with a solution in the shortest possible period of time. The brownfield revitalization purports one of the three possible outcomes: bringing it back to the original intended use, change of the intended use or removal of the existing facilities and ecological cleaning of the terrain. Everything points at a lack of central strategy and earmarked funds, since it is completely clear that the brownfield revitalization surpasses the budget potentials of the local self-governments and sporadic initiatives of the owners of the capital.

\subsection{Mapping of the army brownfield}

A special place in the analysis of the brownfield in Serbia is held by the so-called army brownfield. By looking into the data of the Master Plan of the Ministry of Defence for the facilities intended for conversion $(24 / 01 / 2014$, ), it can be seen that there are 456 complexes currently offered on the market with a total area of $3,814.16$ hectares, that is, 2185 facilities with the total floor space of 440,928 square meters. Most frequently these are representative facilities in downtown zones or facilities that are fully equipped in infrastructural terms (telephone lines, electricity, water, road, railway...), such as military barracks, training fields, airports, warehouses - and as such ideal for being transformed into business infrastructure. The disposal of this real estate is carried out by the Republic Directorate for Assets of the Republic of Serbia in collaboration with the Ministry of Defence, with particular favouring of the local self-government units. According to a decree of the Serbian Government in 2010, the Ministry of Defence cedes to towns and municipalities its assets against a four/five year credit with no interest and banking guarantees, with a special provision that the LSGU may enter into possession as soon as the agreement has been achieved. At the same time, the prices are significantly lower than the market ones. Even with all these incentives, only 66 complexes $(\sim 15 \%$ of the total fund) were sold in the period from the adoption of the plan in 2006 until the end of 2012. Around two thirds of these assets (65\%) were bought by local self-governments, while $35 \%$ were sold through a tender. The poor response and a very slow process go to show that even with all the incentives, the conversion of the army assets completely surpasses the developmental and financial potentials of the local self-governments, which particularly refers to the smaller and undeveloped municipalities.

The total floor space of the BF facilities for which the LSGU (81 out of 144, Belgrade excluded) submitted the data amounts to $2,337,304 \mathrm{~m}^{2}$, while the area of the plots on which these facilities are located amounts to approximately 9,742 hectares. If we add these amounts to the floor space/areas that come out of the analysis of the army brownfield, we will not get a complete picture of the brownfield potentials in Serbia (it is almost certain that the data from the 81 LSGU are not comprehensive, while 63 LSGU have not submit- 
ted their data at all, and Belgrade has not been included in the survey), but we can establish with certainty that on 13,556 ha of land there are mapped brownfield facilities with the floor space of 2,778,232 $\mathrm{m}^{2}$.

\section{Mapping of industrial zones}

The only way to establish the number and structure of the business infrastructure facilities and sites is to set up a unique register within the National Cadastre of Real Estate. The Ministry of Economy and Regional Development in cooperation with the Republic Geodetic Authority initiated in 2011 a project of preliminary design for setting up such register / cadastre, but the implementation of that solution is still far away. Until then, we deal with quite contradictory estimates as to how much of it there is and what the capacity of the business infrastructure facilities and sites in the country is.

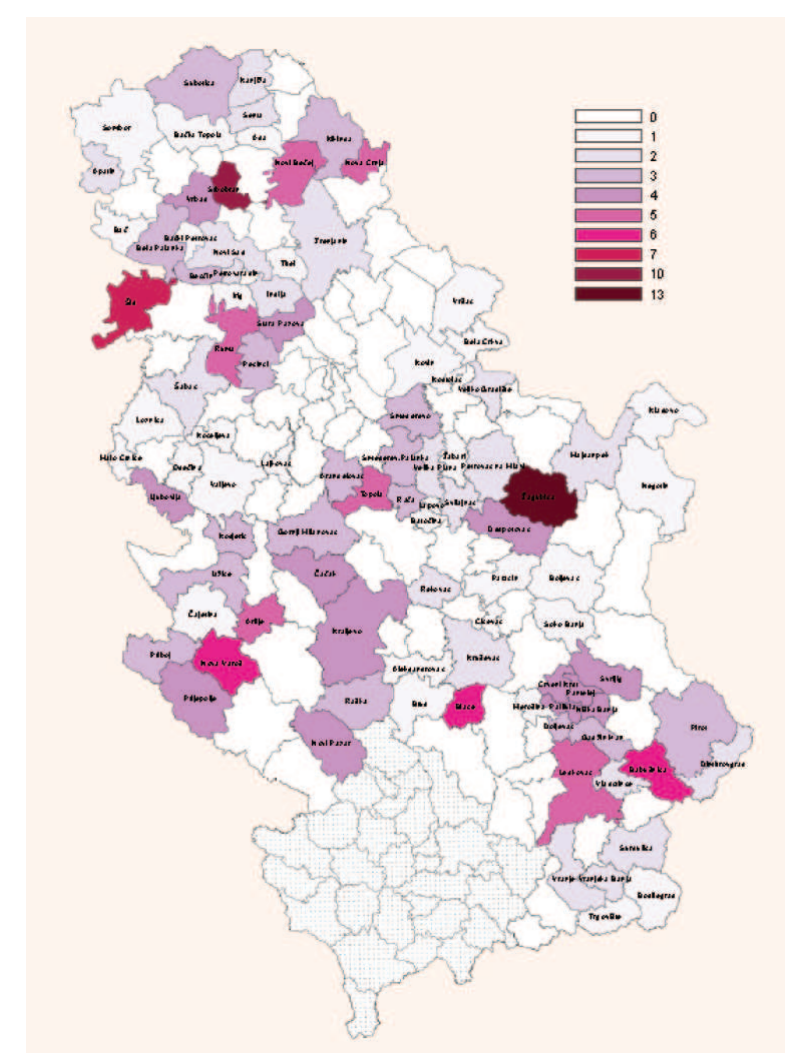

Figure 1: Number of mapped industrial zones

Using the example of industrial zones, even in the official sources we come across very diverse data. According to the Law on Spatial Planning of the Republic of Serbia 2010 - 2020 (page 221), on the territory of the Republic of Serbia (in 81 municipalities and the city of Belgrade) there are 250 existing and planned industrial and investment sites with the area of 13,136 ha, while the site of the line ministry states that in Serbia there are 92 industrial zones.

((http://www.mrrls.gov.rs/sites/default/files/attachment/industrijskezoneuSrbijiMRRLS.pdf))

In the survey conducted in October and November 2013 by the SCTM in cooperation with the local administrations, 91 (63\%) LSGU responded and submitted the data on the total of 245 industrial zones. In addition to the very number of industrial zones, the data were also collected on the areas, degree of equipment with infrastructure, and position in relation to the main traffic lines. Also, the data were collected on the occupied areas and areas that are available for renting out. 


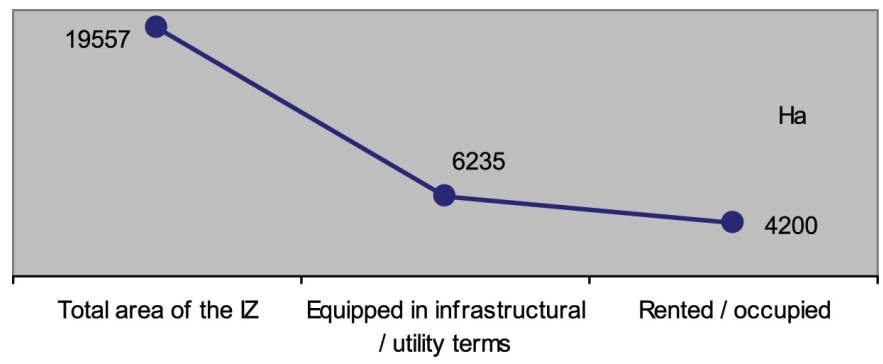

Figure 2: Areas of the mapped IZ / total, equipped in infrastructural terms, and rented out

According to the results of the survey / mapping of industrial zones, the total recorded area amounts to 19,557 ha, with 6,235 ha or $32 \%$ being equipped in infrastructural terms. From the summed up data, it can be seen that so far 4,200 ha have been rented out / occupied, which is $21 \%$ of the total area, that is, $67 \%$ of the areas equipped in infrastructural terms (Figure 2).

When it comes to the position of the industrial zones in relation to the main traffic lines, the average distance from a major road is $1.6 \mathrm{~km}, 51.6 \mathrm{~km}$ from a motorway and $11.2 \mathrm{~km}$ from a railway. The average distance from the closest airport (Surčin or Niš) is $81.8 \mathrm{~km}$ and from the nearest port it is $153.5 \mathrm{~km}$.

Out of the total number of the mapped industrial zones, in $79.6 \%$ of them there is high-voltage network, while $82.9 \%$ have a possibility of connection to the land telephone line. The broadband internet has reached $69.4 \%$, while the gas connection is available in $49 \%$ of the mapped industrial zones. The possibility for enlargement exists in $49 \%$ of the zones.

\section{Analysis of the results with a special view at the brownfield and greenfield}

Even with a very large number of abandoned industrial complexes in Serbia, the majority of the industrial zones have been created as a greenfield investment on agricultural plots which had their intended use changed for that need into industrial land. Only two industrial zones in Serbia have been created through the revitalization of the brownfield - the Old Industrial Zone in Smederevo and "Zastava" plants in Kragujevac. Thus, there are thousands of hectares of agricultural land that were turned in the municipal development documents into industrial zones which are reached by roads, electricity, water, gas, broadband internet, etc.

There are no adopted expenditure standards for equipping industrial zones, given the big differences that are present depending on the location and the existing resources, but on the basis of examples from practice (in Zrenjanin, $€ 5,300,000$ have been spent for equipping 72 ha with infrastructure) the amount for standard equipping of a hectare of industrial zone is $€ 80,000 \pm 20 \%$. During the previous several mandates, the Serbian Government used its budget funds to strongly stimulate the creation and equipping of industrial zones throughout the country. In the period from 2007 to 2010, only from the National Investment Plan, around 20 million euros were invested (table 4) for equipping a number of industrial zones with infrastructure. In the previous year, i.e., in 2013, another 300 million were allocated, while another 450 million dinars are planned for 2014 for equipping a number of industrial zones. (http://akter.co.rs/26-ekonomija/25571-vienovca-za-industrijske-zone.html).

The industrial zones, built in the vicinity of many towns throughout Serbia, were expected to become an engine of the regional development and renewal of the ailing local economy, but it seems that these desires have not been fulfilled completely (Industrial zones - an opportunity or a delusion. Stefan Despotovic, the Politika online 29.09.2013). There are good examples where 2,500 employees have been reached from a barren land over a short period of time (the Niš IZ), but there are also numerous failed cases. Over a million euros have been invested in the Bač Industrial Zone which spreads over 16 hectares ( $€ 65,000 / h a)$. The zone has roads, water, sewerage, electricity and a possibility of gas connection. In order to attract investors, the municipality yielded equipped land for only 60 cents per $\mathrm{m}^{2}(€ 6,000 / \mathrm{ha})$. Most of the 16 lessees got hold of attractive locations next to the major road for little money without any intention of investing into production capacities. According to Tomislav Bogunović, President of the municipality of Bač, some natural persons bought two locations in the industrial zone each which they now use as grazing grounds for their cattle. 
According to the NALED study on the local economic development (Jelena Bojović, Local economic development in Serbia, handbook for practitioners. 2013), unless the dynamics of filling out the industrial zones in Serbia is sped up (600 ha every 10 years), the current offer of land will be sufficient for the next eighty years.

It is completely clear that many more areas in the industrial zones in Serbia have been allocated for the socalled greenfield investments than it is realistically possible to have such investments in the foreseeable future. In addition to the mapping of the land which can always have its intended use changed into agricultural or construction land, much more funds have been spent into this type of attracting investors than it was necessary. Also, it is not realistic that the spent funds will be returned in any foreseeable future through the positive effects of initiating production, employment, creation of new value, etc.

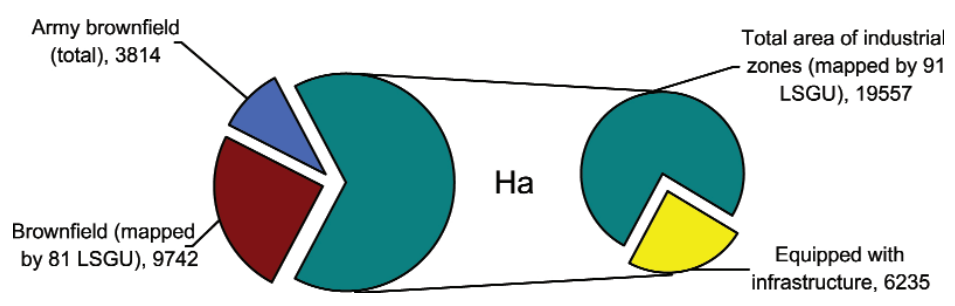

Figure 3: Areas of the mapped brownfield and industrial zones

According to the data collected in the process of the survey carried out by the SCTM, 245 industrial zones (from 91 LSGU) have been mapped with the total area of 19,557 ha out of which 6,235 ha are equipped with infrastructure (Picture 3). Also, 9,742 ha of brownfield areas have been mapped with 2,337,304 $\mathrm{m}^{2}$ of existing facilities which are equipped with infrastructure almost to the same degree as the industrial zones, taking into consideration that this concerns the infrastructure that is already found there. By all relevant criteria, the brownfield sites are on an average better equipped with infrastructure (electricity, water, gas, telephone, internet connection), while the industrial zones have a significant advantage only when it comes to the possibility of enlarging the plot (Figure 3 ).

In the observed period of the industrial zone expansion (and even subsidies of up to $€ 10,000$ for each job post within certain zones), there is a total lack of policies concerning the solving of the issue of the brownfield in Serbia. The stimulation programmes from the central or regional levels with projects that also contain a component of the brownfield facility or site revitalization are very rare. With this lack of plans, programmes and funds, there are very rare examples when investors opted for the brownfield (such as, for instance, when Pompea initiated manufacturing of tights and underwear in the manufacturing units of the former factory "Brusjanka" from Brus), while many towns in Serbia remain captives with depressing views of extinguished factories, crumbling warehouses, manufacturing halls and business buildings.

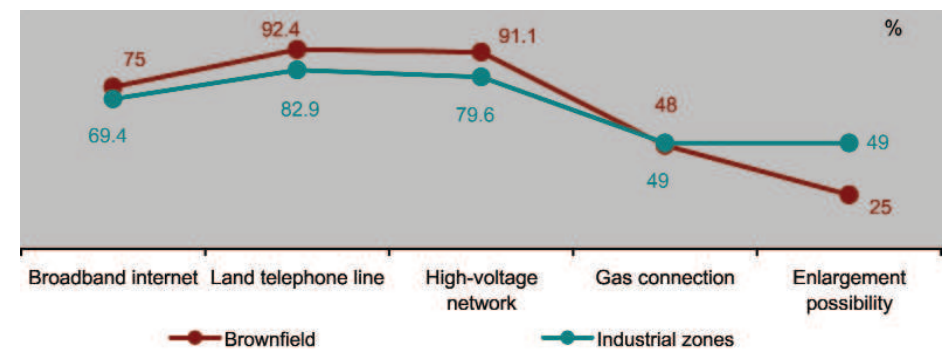

Figure 4: Infrastructural / utility equipment of the mapped brownfield sites and industrial zones (\%)

The data from the SCTM survey referenced in this paper show a major redundancy of the industrial zones and the existing brownfield sites when it comes to the most important investment criterion - distance from the major traffic lines. It may be seen from the summary data on the position in relation to the main traffic lines that most of the industrial zones have been created in the vicinity of the existing brownfield sites. The average distances from a major road or a railway almost coincide, with the industrial zones being on an average slightly closer to a motorway $(9.6 \mathrm{~km})$ and an airport $(28.2 \mathrm{~km})$ in comparison to the brownfield sites. 


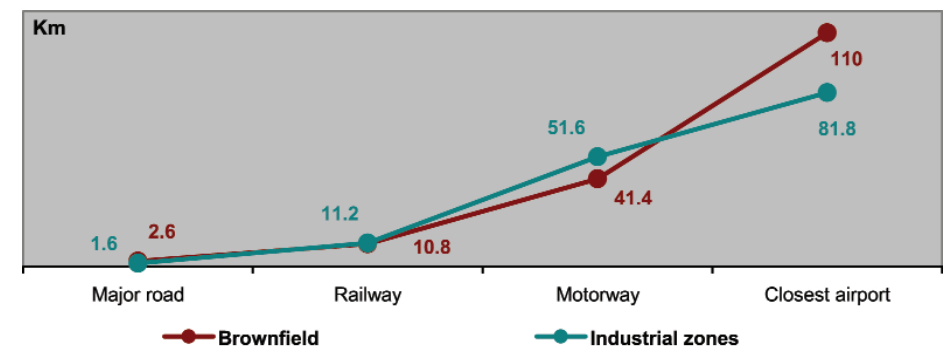

Figure 5: Distance of the mapped brownfield and industrial zones from the major traffic lines

\section{Summary, proposals and recommendations}

The Regional Development Strategy of the Republic of Serbia for the period from 2007 to 2012 puts together the notions of polycentric regional development and stimulation of the SME sector through mapping and construction of business infrastructure. The development of clusters, industrials zones, technological parks, business incubators, logistical and business centres ought to enable a faster and more efficient socio-economic transition which is based on the concept of transposing large enterprises into small- and medium-size ones. It remains unclear why the creators of the economic development in the country accepted that concept and implemented it to the letter, although it was already, in the previous decade, quite clear that the globalization is the main economic stream and that only the "big players" may compete on the global scene. Also, the experience of the countries from the region unquestionably shows that a favourable climate for the development of small- and medium-sized entrepreneurship purports a presence of "big" companies in the close proximity.

As of recently, it is possible to hear more frequently the critical tones regarding the implemented strategies and arguments that point at bad effects of the transposition. The development of the individual elements of business infrastructure has not taken into consideration the real needs and requirements of the small- and mediumsize enterprises and the areas in which they operate, which resulted in an insufficient efficiency in the work, poor effects of raising competitiveness of the enterprises and a lack of long-term stable sources of financing.

The author of the text "Started off and then turned off" emphasizes that the basic goal of founding industrial and technological zones and parks was to increase the competitiveness of the domestic economy and attracting foreign investments. However, owing to the lack of systemic policy in this area, out of 23 registered incubators, only a dozen operate with full capacity and the destiny of the cluster initiatives is almost identical (The Business and Finance magazine, no. 87, May 2012, Source: ).

The data from the survey conducted by the SCTM in collaboration with local administrations is a reliable foundation for drawing conclusions in terms of the set goals of the survey and its methodological framework. The main shortcoming of the implemented methodology is reflected in the missing data from the towns and municipalities that have not responded and therefore it is not possible to get a complete picture of the business infrastructure in Serbia. Taking into account that the records of the total business infrastructure are of essential importance for the institutions that create the local, regional and national development policies, it is to be expected that these issues will earn a systematic and comprehensive approach, that is, that the survey will be continued.

At the same time, the collected data and the results that ensue represent a reliable information basis for drawing essential conclusions and for formulating proposals and recommendations, especially for the sphere of the brownfield and industrial zones:

\section{The main conclusions:}

- There are much more potentials intended for investors than it is realistic to have investors in the foreseeable future.

- Much more funds have been invested in the industrial zones than it was optimal.

- Industrial zones have been favoured in comparison to the brownfield sites.

- Expansion of the brownfield coincides with the period of transition from the socialist economy to the market one, especially through numerous unsuccessful privatizations. 
- Revitalization of the brownfield completely surpasses the potentials of those most hit by the brownfield - the local self-governments.

- Current legal framework does not hinder the brownfield revitalization in Serbia, but neither does it stimulate it.

- Incentives for investors apply to the brownfield as well, but the brownfield revitalization also entails high costs of the land development and rehabilitation, which significantly increases the cost of the investment. According to the current Privatization Law, the rehabilitation costs should be borne by the state, but this mechanism mostly does not function.

Proposals and recommendations:

- Set up a unique register of business infrastructure as a necessary condition for creating an accountable development policy

- Establish the definition of the brownfield and introduce it into the current legal framework.

- Develop mechanisms for assessing the justifiability of investments and on the basis of the drawn conclusions revise the development policy for certain business infrastructure segments.

- Develop tax, planning and promotional instruments at the central level and allocate funds for stimulating revitalization of the brownfield facilities and sites.

- Towns and municipalities ought to have bigger authorities in the process of the brownfield revitalization, such as, for instance, fiscal mechanisms for the demotivation of the owners of the brownfield.

\section{REFERENCES:}

[1] Belkić, V. \& Hrnjaz, M. Local economic development - the European sign-post towards modern local self-government

[2] Bojović, J. (2013). Local economic development in Serbia, handbook for practitioners. Naled.

[3] Bringing the brownfield to life in Serbia. Manual for decision-makers and professionals, the PALGO centre.

[4] Despotović, S. (2013, September). Industrial zones - an opportunity or a delusion. The Politika online.

[5] Initiative for solving the issue of the army brownfield assets in undeveloped municipalities, March 2013

[6] Law on Spatial Plan of the Republic of Serbia from 2010 to 2020.

[7] Mijačić, D. (2011), Analysis of the state of business infrastructure in the Republic of Serbia, Belgrade: National Agency for Regional Development.

[8] Reactivation of the brownfield in Serbia, Systematic approach or ad hoc solutions. SCTM Belgrade (2011)

[9] Regional Development Law. The Official Gazette of the RS no. 51-09

[10] Regional Development Strategy of the Republic of Serbia for the period from 2007. to 2012.

[11] Serbian industry development strategy and policy from 2011 to 2020 . Belgrade

[12] Stošković, M., Nikolić M. \& Djukić, G. (2012). Business infrastructure as a factor of development and competitiveness of small and medium-sized enterprises. Ekonomski Vidici, vol. 17, no. 2, pp. 283-293.

[13] Vukmirović, J.(2013, January). Regional development as a precondition for exiting the crisis. Macroeconomic Analyses and Trends.

[14] Vuković, D. (2009) Low competitiveness of undeveloped areas - the 'bottleneck' of the Serbian economy. Collection of papers of the Geographic Institute "Jovan Cvijic", Serbian Academy of Sciences and Arts vol. 59, no. 2, pp. 189-204. 


\title{
|||||||||||||||||||||||||||||||||| $\mid$ asoutionation
}

\author{
Jovanka Vukmirovic \\ University of Belgrade, Faculty of Organizational Sciences \\ lola@fon.rs
}

Jovanka is assistant professor at the University of Belgrade, Faculty of Organizational Sciences, and professor at Belgrade Business School, Higher Education Institution for Applied Studies. She was the Head of the department for Policy of Regional Development at the Ministry of Economy and Regional Development in Serbia, mainly responsible for creating the Policy of Regional Development founded on relevant statistical indicators from local and regional levels. She was a coordinator in more than one hundred papers, author of many papers of great scientific importance, including the book "Marketing research" (2011).

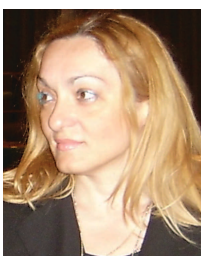

\section{Aleksandra Vukmirovic \\ MSc Stata,rs Itd Belgrade aleksandra.vukmirovic@stata.rs}

Aleksandra is a master engineer of organizational sciences and the General Manager \& Owner of the market research agency Stata.rs. She is the author of several scientific papers of national and international importance, and is currently preparing her $\mathrm{PhD}$ dissertation in the field of electronic business and internet marketing at the University of Belgrade, Faculty of Organizational Sciences.

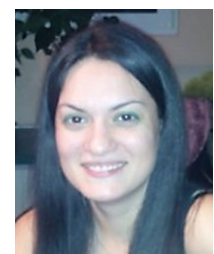

Dragan Vukmirović Belgrade University, Faculty of Organizational Sciences dragan.vukmirovic@stat.gov.rs

Dragan is a Full Professor at the Faculty of Organizational Sciences, Belgrade University and Director of the Statistical Office of the Republic of Serbia. He has published more than one hundred scientific and professional papers in the field of research, statistics, information sciences, marketing, electronic trading and Internet marketing. He participated in and managed a number of empirical studies of the application of quantitative methods in economics and e-commerce. and also participated in the design and implementation of research projects related to these fields of study.

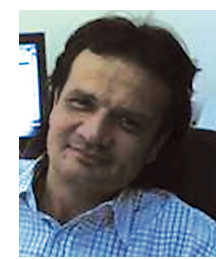

